


\title{
Yabancı uyruklu öğrencilerin öğrenme yaklaşımlarının çeşitli değişkenler açısından incelenmesi ${ }^{1}$
}

Siddık BAKIR ${ }^{2}$

\section{Cengiz ALYILMAZ3}

\begin{abstract}
APA: Bakır, S.; Alyılmaz, C. (2019). Yabancı uyruklu öğrencilerin öğrenme yaklaşımlarının çeşitli değişkenler açısından incelenmesi. RumeliDE Dil ve Edebiyat Araştırmaları Dergisi, (15), 1-14. DOI: 10.29000/rumelide. 580438
\end{abstract}

$\ddot{O} \mathbf{z}$

$\mathrm{Bu}$ araştırmanın amacı, Türkçe hazırlık öğrenimi görmekte olan yabancı uyruklu öğrencilerin öğrenme yaklaşımlarının çeşitli değişkenler açısından incelenmesidir. Araştırma, tarama türünde bir çalışmadır. Araştırmanın evrenini 2013-2014 eğitim öğretim yllında Atatürk Üniversitesi DİLMER, İstanbul Üniversitesi DİLMER ve Gaziantep Üniversitesi TÖMER'de öğrenim gören C1 düzeyindeki yabancı uyruklu öğrenciler oluşturmuştur. Araştırmada, evrenden örneklem alma yoluna gidilmemiş, ilgili çalışılabilir evrendeki C1 düzeyindeki 172 öğrencinin tamamına ulaşılmıştır. Araştırmada veri toplama aracı olarak Senemoğlu (2011) tarafından Türkçeye uyarlanan; geçerlik ve güvenirlik çalışmaları yapılmış olan “Öğrenme Yaklaşımları ve Çalışma Becerileri Ölçeği” kullanılmıştır. Verilerin analiz edilmesi sürecinde, hangi testlerin kullanılacağına karar verebilmek amacıyla öncelikle öğrenme yaklaşımları, yazma becerileri öz yeterlik ölçeğinden elde edilen değerlerin parametrik testlerin temel varsayımlarını karşılayıp karşılayamadıkları incelenmiştir. Bu bağlamda verilerin homojen dağılım sergileyip sergilemediğini belirlemek için Levene homojenlik testi ve normal dağılım için ise Kolmogorov Smirnov normallik testi yapılmıştır. Veri setinin normal dağılım gösterdiği belirlendiği için Bağımsız örneklemler için t testi ve Tek Faktörlü Varyans AnaliziANOVA yapılarak veriler analiz edilmiş ve değişkenler arasındaki ilişkiler ortaya konulmuştur. Değişkenler arasında anlamlı farklılıkların belirlendiği durumlarda çoklu karşılaştırma testlerinden Post Hoc Scheffe ve LSD testleri kullanılarak farkın kaynağı belirlenmeye çalışılmıştır. Veri analizinin tüm aşamalarında $\mathrm{p}=0.05$ değeri kritik değer olarak kabul edilmiştir. Araştırma sonucunda, Türkçe hazırlık öğrenimi görmekte olan yabancı uyruklu öğrencilerin öğrenme yaklaşımlarının cinsiyet, yaş, kitap, gazete, dergi okuma gibi değişkenler açısından anlamlı farklılaşma gösterdiği ortaya konmuştur.

Anahtar kelimeler: Türkçe eğitimi, yabancılara Türkçe öğretimi, öğrenme yaklaşımları.

\footnotetext{
1 Bu makale, 1. yazar tarafindan Prof. Dr. Cengiz Alyılmaz danışmanlığında hazırlanan doktora tezinin bir bölümünden üretilmiștir.

2 Dr. Öğr. Üyesi, Atatürk Üniversitesi Kazım Karabekir Eğitim Fakültesi, Türkçe ve Sosyal Bilimler Eğitimi Bölümü, (Erzurum, Türkiye), siddik.bakir@atauni.edu.tr, ORCID ID: 0000-0002-5118-209X [Makale kayıt tarihi: 14.04.2019kabul tarihi: 16.06.2019; DOI: 10.29000/rumelide. 580438]

3 Prof. Dr., Uludağ Üniversitesi Fen Edebiyat Fakültesi Türk Dili ve Edebiyatı Bölümü, (Bursa, Türkiye), calyilmaz@gmail.com, ORCID ID: 0000-0002-3634-9015.
} 


\title{
Examination of the learning approaches of foreign students in terms of various variables
}

\begin{abstract}
The aim of this study is to examine the learning approaches of foreign students who are studying Turkish preparation in terms of various variables. Research is a type of survey. In the 2013-2014 academic year, the universe of the research was formed by the students of Atatürk University, DILMER, Istanbul University, DILLMER and the students of C1 level, who were educated in Gaziantep University, TÖMER. In this study, 172 students at $\mathrm{C} 1$ level in the relevant workable universe were reached. In this study, the "Learning Approaches and Working Skills Scale" which was adapted to Turkish by Senemoğlu (2011) as a data collection tool was used. In the process of data analysis, in order to determine which tests would be used, learning approaches and the data collected by writing skills self-efficacy measure were tested as to whether they correspond basic assumptions of parametric tests. In this regard, in order to determine whether the data present homogeneous distribution, Levene homogeneity test and for normal distribution; Kolmogorov Smirnov normality test were used. As it was determined that the data set presents a normal distribution, the data were analysed with $\mathrm{t}$ test for independent samples and Single Factoral Variance Analysis, and relations between variances were established. For cases in which reasonable differences were established, By Post HocScheffe and LSD tests out of multiple comparison tests were used to state the source of the difference. The value of $\mathrm{p}=0.05$ was recognized as the critical value in all of the data analysis steps. As a result of the research, it was found that the learning approaches of foreign students who are studying Turkish preparation differ significantly from the variables such as gender, age, book, newspaper, magazine reading.
\end{abstract}

Keywords: Turkish education, teaching Turkish to foreigners, learning approaches.

\section{Giriş}

Bireyin yaşantı, deneyim ve eğitimler sonucu davranışında meydana gelen, çoğunlukla kalıcılık ve süreklilik özelliği de gösteren öğrenme kavramı birçok bilim insanının önemli çalışma alanlarından biri olmuştur. Eğitim-öğretim faaliyetlerinde geçmişten günümüze birçok model, sistem, strateji geliştirilmiş; bunun yanı sıra özellikle eğitim teknolojilerinde yaşanan hızlı değişme ve gelişmelerden eğitim-öğretim alanı da ciddi düzeylerde etkilenmiştir.

Toplumsal yapıda yaşanan değişimlerle bilim ve teknoloji alanındaki gelişmelere bağlı olarak "yaşam boyu öğrenme" kavramı üzerindeki tartışmalar da son yıllarda yoğunluk kazanmıştır. Bununla beraber “birey nasıl öğrenir, en iyi, en etkili öğrenme yöntemi nedir?” benzeri sorular pek çok araştırmanın temel problemi olarak ortaya çıkmıştır. Öğrenenin neyi, nasıl öğrendiğine yönelik yapılan çalışmalar sonucunda öğrenenlerin tamamının aynı yolla öğrenmediği; hatta tamamına yakınının öğrenirken farklı yol ve yöntemler tercih ettikleri kanısına ulaşılmıştır. Hızla yenilenen ve artan bilgi birikiminin tümüne sahip olunamayacağı için bilgiye ulaşmanın ve onu gerektiği yerde kullanmanın en hızlı, en ekonomik yollarını bilmek-öğrenmek bir ihtiyaç hâlini almıştır.

Öğrenme öğretme sürecinden beklenen sonuç, bireylerin eleştirel düşünebilen, mantıksal çıkarımlarda bulunabilen ve herhangi bir konuda özgün fikirler ortaya koyabilen bireyler olarak yetiştirilmesidir. $\mathrm{Bu}$ da bireyin almış olduğu eğitim ve o süreçteki bir konuyu ele alış biçimiyle yakından ilgilidir. Öğrenme 
yaklaşımları olarak isimlendirilen ve öğrenenle öğrenme görevi arasındaki bu etkileşimin ele alınış şekli bir öğrenenden başka bir öğrenene göre farklılık göstermekle beraber öğrenme-öğretme ortamının niteliğine ve özelliklerine göre de değişmektedir.

Yapılan araştırmalarda, öğrenme yaklaşımları bilinen ve buna uygun öğrenme süreci geliştirilen bireylerin eleştirel düşünme yeteneğinin daha çabuk ve kolay geliştiği, bilgiyi daha uzun süreli ve sağllklı saklayabildikleri ve bu bireylerin işe koşulurken daha iyi motive oldukları görülmektedir. Öğrencilerin akademik performanslarını etkileyebileceği düşünülen öğrenme yaklaşımları, bu yönüyle de üzerinde daha çok çalışılması gereken konulardan biri olarak karşımıza çıkmaktadır.

İlgili literatürde, öğrenme yaklaşımları, yüzeysel (surface), derinlemesine (deep) ve stratejik (strategic) olmak üzere üçe ayrılmaktadır. Bu üç yaklaşımdan ilk ikisi olan yüzeysel ve derinlemesine öğrenme yaklaşımları İsveçli bilim insanları Marton ve Saljo (1976) tarafından, üçüncü yaklaşım olan stratejik öğrenme yaklaşımı da İngiliz bilim insanları Entwistle ve Ramsden (1983) tarafından yapılan çalışmalarla ortaya konmuştur. Entwistle ve Ramsden, Marton ve Saljo'nun yapmış oldukları önceki çalışmalardan farklı olarak nicel araştırma yöntemlerini de kullanmış ve ilk bulguları destekleyen sonuçlar ortaya koymuşlardır (Kılıç, 2009).

Öğrencilerin çalışma yaklaşımlarının belirlenmesine yönelik birbirlerinden bağımsız olarak ölçme araçları geliştiren ve uygulayan bilim adamları, öğrenme yaklaşımlarının bu üç farklı boyutu olduğunu öne sürmüşlerdir. Farklı araştırma yöntemleri kullanılmasına karşın benzer bulgulara ulaşılması, geliştirilen kavramların geçerliliğini artıran bir sonuç olarak değerlendirilmektedir (Newble ve Entwistle, 1986).

Öğrencilerin akademik bir makaleyi okuma işini nasıl ele aldıklarını araştıran Marton ve Saljo (1976) deneysel özellikteki çalışmalarında, öğrencilerle görüşmeler yapmış ve öğrencilerin makaleyi okumaya nasıl yaklaştıklarını, okuma sırasındaki davranışlarını ve okuduktan sonra neler öğrendiklerini belirlemeye çalışmışlardır. Yaptıkları araştırma sonucunda, öğrencilerin öğrenmeyi ele alış biçimlerinin temelinde yüzeysel ve derinlemesine öğrenme yaklaşımlarının olduğunu değerlendirmişlerdir.

Çalışma konularını öğrenmek ve anlamak için büyük çaba gösteren öğrencilerin yanı sıra dersi geçebilecek kadar gayret gösteren öğrencilerin olduğunu ve öğretmenlerin de bu durumun farkında olduklarını belirten Biggs'in (1987) makalesinde belirtilmek istenen de öğrenenlerin, öğrenmeye gösterdikleri farklı tutumun, seçtikleri yöntemin birbirinden farklı olduğu ve her bir öğrenenin öğrenme ödevini farklı bir yaklaşımla ele aldığıdır. Bu da beraberinde öğrenme yaklaşımlarıyla ilgili birçok bilimsel çalışma yapılmasını zorunlu hâle getirmiştir (Çolak ve Fer, 2007).

Ramsden'e (1992) göre öğrenme yaklaşımları ile ilgili birçok yanlış anlama da söz konusudur. Yüzeysel öğrenme yaklaşımı ile düşük yeteneğin ilişkili olduğuna, yüzeysel ve derinlemesine öğrenme yaklaşımlarının birbirinin tamamlayıcısı olduğuna; ayrıca öğrenme yaklaşımının kişisel bir özellik olduğuna yönelik görüşlerin gerçeği yansıtmadığını belirten Ramsden (1992), bir öğrencinin bazen derinlemesine öğrenme yaklaşımını bazen de yüzeysel öğrenme yaklaşımını tercih edebileceğini, bazı durumlarda da bir yaklaşımdan diğer bir yaklaşıma geçebileceğini; bunun sabit, kişisel bir özellik ve yetenekle ilgili olmadığını ifade etmektedir.

Bunun yanı sıra bazı araştırmacılara (Jackson, 1994; Scouller, 1998) göre "niyet, amaç" olarak da değerlendirilen öğrenme yaklaşımlarını sürekli karıştırılan öğrenme stillerinden ayıran unsurlar da 
yukarıda açıklanmaya çalışılan gerekçelerdir (Ekinci, 2008). Öğrenme yaklaşımı, bir kişilik özelliği gibi görünse ve öğrenenin kişilik özelliklerinden sınırlı şekilde etkilense de aslında tam anlamıyla bir kişilik özelliğidir denilemez. Öğrenme stilleri ile farklılaşan başlıca özelliğinin de bu olduğu söylenebilir. Çünkü öğrenme stilleri her ne kadar sabit kişilik özellikleri olarak dikkate alınmasa da kalıcı kişilik özellikleri olarak değerlendirilmektedir. Bu kalıcı kişilik özellikleri, biçimleri bireyin çevresiyle olan etkileşiminin sonucu olarak süreklilik kazanmaktadır (Demirel, 2000).

Öğrenme yaklaşımları, “öğrenen veya alıcı” ile “ortam” arasındaki ilişkiye göre şekillenir. Öğrenen veya alıcı, ortamın özellikleri ile ortamı algılama düzeyi ve türüne göre bir ortamda yüzeysel, başka bir ortamda stratejik veya bir başka ortamda derinlemesine yaklaşımı rahatlıkla tercih edebilmektedir. Bundan dolayı da öğrenme yaklaşımları, öğrenme stillerinden farklılık göstermektedir. Öğrenme stilleri ise ortam fark etmeksizin değişmeyen, her şart ve koşulda aynı kalan bireysel özelliklere uygun olarak değerlendirilmektedir (Marshall ve Case, 2007).

\subsection{Araştırmanın amacı}

Bu çalışmanın amacı, Türkçe hazırlık programına devam etmekte olan yabancı uyruklu öğrencilerin öğrenme yaklaşımlarını incelemektir. Bu amaca uygun olarak aşağıdaki sorulara cevap aranmıştır.

Türkçe hazırlı programına devam etmekte olan yabancı uyruklu öğrencilerin öğrenme yaklaşımlarındaki tercihleri;

Cinsiyetlerine,

Yaşlarına,

Türkçe kitap, gazete, dergi okuma durumlarına,

En iyi olduklarını düşündükleri beceri alanlarına,

Türkiye’ye gelmeden önce Türkçe eğitimi alma durumlarına,

Türkçe öğrenme konusundaki düşüncelerine,

Türk televizyonlarını izleme durumlarına,

Türkçe yazma durumlarına göre farklılaşmakta mıdır?

\section{Yöntem}

\subsection{Araşturma modeli}

$\mathrm{Bu}$ araştırmada, nicel araştırma yöntemlerinden tarama modeli kullanılmıştır. Tarama modeli, geçmişte ya da günümüzde var olan bir durumu olduğu şekliyle tasvir etmeyi amaçlayan bir araştırma yaklaşımıdır. Araştırmaya konu olan birey ya da nesne, kendi şartları içinde ve olduğu şekilde tanımlanmaya çalışılır ve herhangi bir şekilde değiştirme, etkileme çabası gösterilmez (Karasar, 2012).

\subsection{Evren ve örneklem}

$\mathrm{Bu}$ araştırmada örneklem alma yoluna gidilmemiş; evrenin tamamına ulaşılmaya çalışılmıştır. Araştırmanın evreni, Atatürk Üniversitesi DİLMER, İstanbul Üniversitesi DİLMER ve Gaziantep Üniversitesi TÖMER'de hazırlık öğrenimi görmekte olan C1 düzeyindeki yabancı uyruklu öğrencilerden oluşmaktadır. Araştırmanın evreni yaklaşık 190 öğrenciden oluşmaktadır. Bu öğrencilerin tamamına ölçek uygulanmış ancak yapılan inceleme sonucunda 172 öğrenciye ait ölçeğin analize uygun olduğu ve 18 kişiye ait ölçeğin çok fazla sayıda boşluk içermesi nedeniyle değerlendirmeye alınmamasına karar 
verilmiş ve toplamda 172 kişiden alınan ölçekler üzerinden veri analizleri yapılmıştır. Araştırma evrenine ilişkin betimsel değerler Tablo 1'de gösterilmektedir.

Tablo 1. Araştırmanın Evrenine İlişkin Betimsel Değerler

\begin{tabular}{llll}
\hline Üniversite & Öğrenci sayısı & & \\
\cline { 2 - 3 } & Kız & Erkek & Toplam \\
\hline Atatürk Üniversitesi & 32 & 53 & 85 \\
İstanbul Üniversitesi & 19 & 30 & 49 \\
Gaziantep Üniversitesi & 14 & 24 & 38 \\
Toplam & 75 & 107 & 172 \\
\hline
\end{tabular}

\subsection{Veri toplama aracı}

Araştırma verileri 2013-2014 eğitim öğretim yılı Mayıs-Eylül dönemi arasında C1 düzeyinde başarılı adaylardan toplanmıştır. Senemoğlu (2011) tarafından Türkçeye uyarlanan; geçerlik ve güvenirlik çalışmaları yapılmış olan “Öğrenme Yaklaşımları ve Çalışma Becerileri Ölçeği” kullanılmıştır.

Ölçek, Tait, Enwistle ve McCune (1998) tarafından geliştirilen ve Senemoğlu (2011) tarafından Türkçeye uyarlanan öz bildirime dayalı likert tipi bir ölçme aracıdır. Toplamda dört bölümden oluşan ölçeğin birinci bölümünde derinlemesine, stratejik ve yüzeysel öğrenmeyi ölçen üç alt boyut bulunmaktadır. İkinci bölümde öğrenme kavramına yüklenen anlam, üçüncü bölümde öğrencilerin farklı türdeki ders ve öğretime ilişkin tercihleri ölçülmektedir. Dördüncü bölümde ise öğrencilerin kendilerini akademik başarı yönü ile değerlendirmelerine yönelik maddeler bulunmaktadır. Ölçeğin Türkçeye uyarlama sürecinde elde edilen iç tutarlık değerleri ölçeğin toplamı ve alt boyutlar için .71 ve .91 arasındadır. Ölçeğin Ozan ve Çiftçi (2013) tarafından bir diğer güvenirlik çalışmasında ölçeğin bütünü için güvenirlik değeri .84 olarak ve alt boyutlar için sırasıyla $.73, .85$ ve .74 olarak bulunmuştur. Bu araştırmadan elde edilen iç tutarlılık katsayıları da .70 ve .88 arasındadır.

\subsection{Verilerin analizi}

Verilerin analizinde öncelikle normallik varsayımları karşılanıp karşılanmadığı kontrol edilmiştir. Normallik testlerinden Kolmogorov-Smirnov testi yapılmıştır. Verilerin homojen dağılım gösterip göstermediği ise Levene testi aracılığı ile kontrol edilmiştir. Yapılan analizler sonucunda verilerin normal dağılıma uygun olduğu ve homojen dağıldığı belirlenmiş ve parametrik testlerin kullanılmasına karar verilmiştir. Verilerin analizinde bağımsız örneklemler için t-testi ve tek yönlü varyans analizi kullanılmıştır. Anlamlı farklılıkların olduğu durumlarda da çoklu karşılaştırma testlerinden Post Hoc testlerinden Scheffe testi kullanılmıştır. Veri analizinin tüm aşamalarında $\mathrm{p}=0.05$ değeri kritik değer olarak kabul edilmiştir.

\section{Bulgular ve yorumlar}

Türkçe hazırlık öğrenimi görmekte olan öğrencilerin öğrenme yaklaşımlarının cinsiyet değişkenine göre anlamlı farklılık gösterip göstermediğini belirleme amacıyla bağımsız örneklemler için t-testi yapılmış ve sonuçlar Tablo 1'de gösterilmiştir. 
Tablo 2. Cinsiyet Değişkenine Göre Öğrenme Yaklaşımlarının Farklılaşma Durumu

\begin{tabular}{lllllll}
\hline & Cinsiyet & $\mathrm{N}$ & $\bar{X}$ & $\mathrm{ss}$ & $\mathrm{t}$ & $\mathrm{p}$ \\
\hline \multirow{2}{*}{ Derinlemesine } & Kiz & 65 & 69.05 & 11.14 & & \\
& Erkek & 107 & 72.87 & 12.85 & -1.983 & $\mathbf{. 0 4 9}$ \\
\hline \multirow{2}{*}{ Stratejik } & Kiz & 65 & 69.90 & 11.26 & & \\
& Erkek & 107 & 74.12 & 12.24 & -2.255 & $\mathbf{. 0 2 5}$ \\
\multirow{2}{*}{ Yüzeysel } & Kiz & 65 & 62.96 & 11.72 & & \\
& Erkek & 107 & 66.79 & 12.58 & -1.990 & $\mathbf{. 0 4 8}$ \\
\hline
\end{tabular}

Tablo 2 incelendiğinde, öğrencilerin öğrenme yaklaşımlarının cinsiyetlerine göre anlamlı bir farklılık gösterdiği görülmektedir ( $<$.05). Buna göre her üç öğrenme yaklaşımında da erkek öğrencilerin lehine anlamlı farlılığın olduğu aritmetik ortalamalardan anlaşılmaktadır (Derinlemesine Yaklaşım $\bar{X}$ Kız $=69,05, \bar{X}_{\text {Erkek }}=72,87$; Stratejik Yaklaşım $\bar{X}_{\mathrm{Klz}}=69,90, \bar{X}_{\text {Erkek }}=74,12$; Yüzeysel Yaklaşım $\bar{X}_{\mathrm{Kuz}}=62,96$, $\left.\bar{X}_{\text {Erkek }}=66,79\right)$

Türkçe hazırlık öğrenimi görmekte olan öğrencilerin öğrenme yaklaşımlarının yaşlarına göre anlamlı farklılaşma gösterip göstermediğini belirlemek için Tek Faktörlü Varyans Analizi- ANOVA yapılmış ve sonuçlar Tablo 3 ve Tablo 4’te gösterilmiştir.

Tablo 3. Yaş Değişkenine Göre Öğrencilerin Öğrenme Yaklaşımlarının Aritmetik Ortalama ve Standart Sapma Değerleri

\begin{tabular}{lllll}
\hline Yaklaşım & Yaş & N & $\bar{X}$ & ss \\
\hline \multirow{2}{*}{ Derinlemesine } & $16-20$ & 93 & 70.63 & 13.27 \\
& $21-26$ & 55 & 72.86 & 11.71 \\
& $27-30$ & 19 & 71.12 & 10.28 \\
& 31 üstü & 5 & 71.75 & 9.38 \\
\hline Stratejik & $16-20$ & 172 & 71.43 & 12.34 \\
& $21-26$ & 93 & 72.28 & 12.85 \\
& $27-30$ & 55 & 73.53 & 11.91 \\
Yüzeysel & 31 üstü & 19 & 71.11 & 8.27 \\
\hline $16-20$ & 5 & 71.60 & 11.59 \\
& $21-26$ & 172 & 72.53 & 12.02 \\
& $27-30$ & 93 & 66.04 & 12.15 \\
\hline
\end{tabular}

Tablo 3'te, Türkçe hazırlık sınıfı öğrencilerinin öğrenme yaklaşımlarına ilişkin aritmetik ortalama ve standart sapma değerleri verilmiştir. Yaş değişkenine göre aritmetik ortalamalar arasında anlamlı farklılık olup olmadığını belirlemek için tek yönlü varyans analizi (ANOVA) yapılmış ve elde edilen bulgular Tablo 4’te verilmiştir. 
Tablo 4. Yaş Değişkenine Göre Tek Faktörlü ANOVA Sonucu

\begin{tabular}{lllllll}
\hline & & Kareler toplamı & sd & Kareler ortalaması & F & p \\
\hline \multirow{2}{*}{ Derinlemesine } & Gruplar arası & 174.663 & 3 & 58.221 & .378 & .769 \\
& Gruplar içi & 25864.972 & 168 & 153.958 & & \\
& Toplam & 26039.635 & 171 & & .235 & .872 \\
\hline \multirow{2}{*}{ Stratejik } & Gruplar arası & 103.425 & 3 & 34.475 & 146.532 & \\
& Gruplar içi & 24617.430 & 168 & & & .232 \\
& Toplam & 24720.855 & 171 & 36.004 & .874 \\
\hline
\end{tabular}

Tablo 4 incelendiğinde, Türkçe hazırlık sınıfı öğrencilerinin öğrenme yaklaşımlarının yaş değişkenine

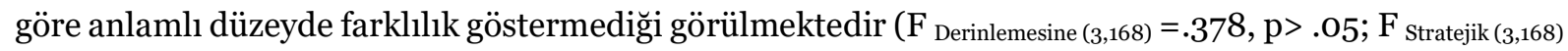

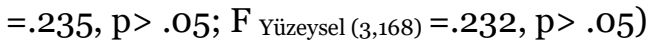

Türkçe hazırlı öğrenimi görmekte olan öğrencilerin öğrenme yaklaşımlarının Türkçe gazete, dergi ve kitap okuma değişkenine göre anlamlı farklılaşma gösterip göstermediğini belirlemek için bağımsız örneklemler için t testi yapılmış ve sonuçlar Tablo 5 ’te verilmiştir.

Tablo 5. Kitap, Gazete ve Dergi Okuma Değişkenine Göre Öğrencilerin Öğrenme Yaklaşımlarının Farklılaşma Durumu

\begin{tabular}{lllllll}
\hline & Okuma & $\mathrm{N}$ & $\bar{X}$ & $\mathrm{ss}$ & $\mathrm{t}$ & $\mathrm{p}$ \\
\hline \multirow{2}{*}{ Derinlemesine } & Evet & 143 & 71.86 & 12.43 & & \\
\hline \multirow{2}{*}{ Stratejik } & Hayır & 29 & 69.31 & 11.83 & 1.015 & .311 \\
\hline \multirow{2}{*}{ Yüzeysel } & Evet & 143 & 73.00 & 12.21 & & \\
& Hayir & 29 & 70.17 & 10.90 & 1.159 & .248 \\
\hline
\end{tabular}

Tablo 5 incelendiğinde, öğrencilerin Öğrenme yaklaşımları ve çalışma becerilerinin kitap, gazete ve dergi okuma değişkenine göre sadece Yüzeysel Yaklaşım alt boyutunda anlamlı farklılaşma gösterdiği görülmektedir $\left(\mathrm{t}_{(170)}=2,122, \mathrm{p}<.05\right)$. Buna göre, yüzeysel yaklaşım alt boyutunda kitap, gazete ve dergi okuyanların aritmetik ortalamasının $\bar{X}=66,24$ ve okumayanların aritmetik ortalamasının ise $\bar{X}$ =60,94 olduğu ve Türkçe kitap, gazete ve dergi okuyanların okumayanlara göre yüzeysel yaklaşımı daha fazla tercih ettikleri söylenebilir.

Türkçe hazırlık öğrenimi görmekte olan öğrencilerin öğrenme yaklaşımlarının en iyi olduklarını düşündükleri beceri alanı değişkenine göre anlamlı farklılaşma gösterip göstermediğini belirlemek için tek faktörlü varyans analiz yapılmış ve sonuçlar Tablo 5 ve Tablo 6'da gösterilmiştir. 
Tablo 6. Türkçe Öğrenen Yabancı Uyruklu Öğrencilerin En İyi Olduklarını Düşündükleri Beceri Alanı Değişkenine Göre Öğrencilerin Öğrenme Yaklaşımlarının Aritmetik Ortalama ve Standart Sapma Değerleri

\begin{tabular}{lllll}
\hline Yaklaşım & Beceri & $\mathrm{N}$ & $\bar{X}$ & ss \\
\hline \multirow{2}{*}{ Derinlemesine } & Okuma & 49 & 71.43 & 12.96 \\
& Yazma & 24 & 71.56 & 12.83 \\
& Konuşma & 51 & 69.90 & 13.18 \\
& Dil bilgisi & 25 & 71.65 & 11.06 \\
& Dinleme & 23 & 74.46 & 10.09 \\
\hline \multirow{3}{*}{ Stratejik } & Okuma & 49 & 70.96 & 13.41 \\
& Yazma & 24 & 71.92 & 12.88 \\
& Konuşma & 51 & 72.24 & 12.08 \\
& Dil bilgisi & 25 & 75.00 & 9.85 \\
& Dinleme & 23 & 74.48 & 10.13 \\
\hline Yüzeysel & Okuma & 49 & 65.64 & 13.06 \\
& Yazma & 24 & 65.78 & 11.08 \\
& Konuşma & 51 & 64.71 & 12.85 \\
& Dil bilgisi & 25 & 63.65 & 11.97 \\
& Dinleme & 23 & 67.55 & 12.13 \\
\hline
\end{tabular}

Tablo 6'da, Türkçe hazırlık sınıfı öğrencilerinin en iyi olduklarını düşündükleri beceri alanı değişkenine ilişkin aritmetik ortalama ve standart sapma değerleri verilmiştir. Öğrencilerin en iyi olduklarını düşündükleri beceri alanına ilişkin aritmetik ortalamalar arasında anlamlı farklılaşma olup olmadığını belirlemek için tek yönlü varyans analizi (ANOVA) uygulanmış ve elde edilen bulgular Tablo 7’de verilmiştir.

Tablo 7. Türkçe Öğrenen Yabancı Uyruklu Öğrencilerin Öğrenme Yaklaşımlarının En İyi Olduklarını Düşündükleri Beceri Alanı Değişkenine Göre Farklılaşma Durumuna Yönelik ANOVA Sonucu

\begin{tabular}{lllllll}
\hline & & Kareler toplamı & sd & Kareler Ortalaması & F & p \\
\hline \multirow{4}{*}{ Derinlemesine } & Gruplar arası & 331.387 & 4 & 82.847 & & \\
& Gruplar içi & 25708.248 & 167 & 153.942 & .538 & .708 \\
& Toplam & 26039.635 & 171 & & & \\
\hline \multirow{3}{*}{ Stratejik } & Gruplar arası & 374.187 & 4 & 93.547 & & \\
& Gruplar içi & 24346.667 & 167 & 145.788 & .642 & .634 \\
& Toplam & 24720.855 & 171 & & & \\
\hline \multirow{3}{*}{ Yüzeysel } & Gruplar arası & 213.690 & 4 & 53.423 & & \\
& Gruplar içi & 25956.005 & 167 & 155.425 & .344 & .848 \\
& Toplam & 26169.695 & 171 & & & \\
\hline
\end{tabular}

Tablo 7 incelendiğinde, Türkçe hazırlık sınıfı öğrencilerinin en iyi olduklarını düşündükleri beceri alanı değişkenine göre öğrenme yaklaşımları arasında anlamlı farklılaşma olmadığı görülmektedir (F Derinlemesine $(4,167)=.538, \mathrm{p}>.05 ; \mathrm{F}$ Stratejik $(4,167)=.642, \mathrm{p}>.05 ; \mathrm{F}$ Yüzeysel $(4,167)=.848, \mathrm{p}>.05)$. Buna göre 
öğrencilerin öğrenme yaklaşımları üzerinde en iyi olduklarını düşündükleri beceri alanı değişkeninin anlamlı bir etkisinin olmadı̆̆ söylenebilir.

Türkçe hazırlı öğrenimi görmekte olan öğrencilerin öğrenme yaklaşımlarının önceden Türkçe eğitimi almış olma değişkenine göre anlamlı farklılaşma gösterip göstermediğini belirlemek için bağımsız örneklemler için t testi yapılmış ve sonuçlar Tablo 8'de verilmiştir.

Tablo 8. Önceden Türkçe Eğitimi Almış Olma Değişkenine Göre Öğrenme Yaklaşımların Farklılaşma Durumu

\begin{tabular}{lllllll}
\hline & Ĕ̆itim & $\mathrm{N}$ & $\bar{X}$ & $\mathrm{ss}$ & $\mathrm{t}$ & $\mathrm{p}$ \\
\hline \multirow{2}{*}{ Derinlemesine } & Evet & 54 & 72.82 & 11.05 & & \\
\hline \multirow{2}{*}{ Stratejik } & Hayır & 118 & 70.79 & 12.88 & 1.001 & .318 \\
\hline \multirow{2}{*}{ Yüzeysel } & Evet & 54 & 73.89 & 11.32 & & \\
\hline & Hayır & 118 & 71.91 & 12.33 & 1.003 & .317 \\
\hline
\end{tabular}

Tablo 8 incelendiğinde, öğrencilerin öğrenme yaklaşımlarının önceden Türkçe eğitim almış olma değişkenine göre anlamlı olarak farklılaşma göstermediği görülmektedir $\left(\mathrm{t}_{\text {Derinlemesine(172) }}=1.001, \mathrm{p}>.05\right.$; $\mathrm{t}$ Stratejik (172) $=1.003, \mathrm{p}>.05 ; \mathrm{t}$ Yüzeysel(172) $=.396, \mathrm{p}>.05)$. Elde edilen bu bulgu doğrultusunda, önceden Türkçe eğitim almış olmanın öğrenme yaklaşımları üzerinde anlamlı bir farklılık göstermediği söylenebilir.

Türkçe hazırlık öğrenimi görmekte olan öğrencilerin öğrenme yaklaşımlarının Türkçenin zorluğuna ilişkin düşünce değişkeni açısından anlamlı farklılaşma gösterip göstermediğini belirlemek için bağımsız örneklemler için t testi yapılmış ve sonuçlar Tablo 9'da gösterilmiştir.

Tablo 9. Türkçe Öğrenmenin Zorluğuna İlişkin Düşünce Değişkenine Göre Öğrenme Yaklaşımlarının Farklılaşma Durumu

\begin{tabular}{|c|c|c|c|c|c|c|}
\hline & Zorluk & $\mathrm{N}$ & $\bar{X}$ & SS & $\mathrm{t}$ & $\mathrm{p}$ \\
\hline \multirow{2}{*}{ Derinlemesine } & Evet & 40 & 69.63 & 11.19 & \multirow{2}{*}{-1.057} & \multirow{2}{*}{.292} \\
\hline & Hayır & 132 & 71.98 & 12.66 & & \\
\hline \multirow{2}{*}{ Stratejik } & Evet & 40 & 70.68 & 13.19 & \multirow{2}{*}{-1.114} & \multirow{2}{*}{.267} \\
\hline & Hayır & 132 & 73.09 & 11.64 & & \\
\hline \multirow{2}{*}{ Yüzeysel } & Evet & 40 & 62.16 & 13.89 & \multirow{2}{*}{-1.877} & \multirow{2}{*}{.062} \\
\hline & Hayır & 132 & 66.32 & 11.76 & & \\
\hline
\end{tabular}

Tablo 9 incelendiğinde, öğrencilerin öğrenme yaklaşımlarının Türkçe öğrenmenin zorluğuna ilişkin düşüncelerine göre anlamlı olarak farklılaşma göstermediği görülmektedir ( $t$ Derinlemesine(172) $=-1.057$, $\mathrm{p}>.05 ; \mathrm{t}_{\text {Stratejik(172) }}=-1.114, \mathrm{p}>.05 ; \mathrm{t}_{\text {Yüzeysel(172) }}=-1.877, \mathrm{p}>.05$ ). Elde edilen bu bulgu doğrultusunda, Türkçe öğrenmenin zorluğuna ilişkin düşüncelerin öğrenme yaklaşımları üzerinde anlamlı bir farklılık göstermediği söylenebilir. 
Türkçe hazırlık öğrenimi görmekte olan öğrencilerin öğrenme yaklaşımlarının Türkçe televizyon yayınlarını izleme değişkeni açısından anlamlı farklılaşma gösterip göstermediğini belirlemek için bağımsız örneklemler için t testi yapılmış ve sonuçlar Tablo 10'da verilmiştir.

Tablo 1o. Türkçe Televizyon Yayını İzleme Değişkenine Göre Öğrenme Yaklaşımlarının Farklılaşma Durumu

\begin{tabular}{lllllll}
\hline & Tv & $\mathrm{N}$ & $\bar{X}$ & $\mathrm{ss}$ & $\mathrm{t}$ & $\mathrm{p}$ \\
\hline \multirow{2}{*}{ Derinlemesine } & Evet & 127 & 71.97 & 12.29 & \multirow{2}{*}{.069} & .306 \\
& Hayır & 44 & 69.66 & 12.51 & & \\
\multirow{2}{*}{ Stratejik } & Evet & 127 & 72.81 & 11.87 & \multirow{2}{*}{.556} & .579 \\
\hline \multirow{2}{*}{ Yüzeysel } & Hayır & 44 & 71.64 & 12.67 & & .555 \\
\hline
\end{tabular}

Tablo 10 incelendiğinde, öğrencilerin öğrenme yaklaşımlarının Türkçe televizyon yayını izleme değişkenine göre anlamlı olarak farklılaşma göstermediği görülmektedir $(\mathrm{t}$ Derinlemesine $(172)=1.069, \mathrm{p}>.05$; $\mathrm{t}_{\text {Stratejik(172) }}=.556, \mathrm{p}>.05 ; \mathrm{t}$ Yüzeysel(172) $=.591, \mathrm{p}>.05$ ). Elde edilen bu bulgu doğrultusunda, Türkçe televizyon yayını izlemenin öğrenme yaklaşımları üzerinde anlamlı bir farklılık göstermediği söylenebilir.

Türkçe hazırlık öğrenimi görmekte olan öğrencilerin öğrenme yaklaşımlarının Türkçe yazma değişkenine göre anlamlı farklılaşma gösterip göstermediğini belirlemek için bağımsız örneklemler için $\mathrm{t}$ testi yapılmış ve sonuçlar Tablo 11'de verilmiştir.

Tablo 11. Türkçe Yazma Değişkenine Göre Öğrenme Yaklaşımlarının Farklılaşma Durumu

\begin{tabular}{|c|c|c|c|c|c|c|}
\hline & Yazma & $\mathrm{N}$ & $\bar{X}$ & ss & $\mathrm{t}$ & $\mathrm{p}$ \\
\hline \multirow[b]{2}{*}{ Derinlemesine } & Evet & 54 & 70.56 & $14 \cdot 31$ & \multirow{2}{*}{-.700} & \multirow{2}{*}{.485} \\
\hline & Hayır & 117 & 71.98 & 11.31 & & \\
\hline \multirow[b]{2}{*}{ Stratejik } & Evet & 54 & 72.04 & 13.69 & \multirow{2}{*}{-.412} & \multirow{2}{*}{.681} \\
\hline & Hayır & 117 & 72.86 & 11.23 & & \\
\hline \multirow{2}{*}{ Yüzeysel } & Evet & 54 & 66.32 & 13.16 & \multirow{2}{*}{.637} & \multirow{2}{*}{.525} \\
\hline & Hayır & 117 & 65.02 & 12.01 & & \\
\hline
\end{tabular}

Tablo 11 incelendiğinde, öğrencilerin öğrenme yaklaşımlarının Türkçe yazma değişkenine göre anlamlı olarak farklılaşma göstermediği görülmektedir $\left(\mathrm{t}_{\text {Derinlemesine }(171)}=-.700, \mathrm{p}>.05\right.$; $\mathrm{t}_{\text {Stratejik(171) }}=-.412, \mathrm{p}>.05$; $\mathrm{t}$ Yüzeysel(171) $=.637, \mathrm{p}>.05)$. Elde edilen bu bulgu doğrultusunda, Türkçe yazı yazmanın öğrenme yaklaşımları üzerinde anlamlı bir etkiye sahip olmadığı söylenebilir.

\section{Sonuç ve öneriler}

Elde edilen bulgular doğrultusunda, Türkçe hazırlık öğrenimi görmekte olan yabancı uyruklu öğrencilerin Öğrenme Yaklaşımlarına ilişkin şu sonuçlar ortaya çıkmaktadır:

Yabancı uyruklu öğrencilerin öğrenme yaklaşımlarının cinsiyetlerine göre anlamlı olarak bir farklılık gösterdiği görülmektedir. Buna göre, Derinlemesine Yaklaşım alt boyutunda kızların aritmetik 
ortalamasının ( $\bar{X}=69,05)$ ve erkeklerin aritmetik ortalamasının ise ( $\bar{X}=72,87)$ olduğu ve erkeklerin derinlemesine yaklaşımı kızlara göre anlamlı olarak daha fazla kullandıkları söylenebilir. Stratejik Yaklaşım alt boyutunda ise kızların aritmetik ortalamasının $(\bar{X}=69,90)$ ve erkeklerin aritmetik ortalamasının ( $\bar{X}=74,12)$ olduğu ve erkeklerin stratejik yaklaşımı kızlara göre anlamlı olarak daha fazla kullandıkları söylenebilir. Yüzeysel Yaklaşım alt boyutunda ise kızların aritmetik ortalamasının ( $\bar{X}$ $=62,96)$ ve erkeklerin aritmetik ortalamasının $(\bar{X}=66,79)$ olduğu ve erkeklerin yüzeysel yaklaşımı kızlara göre anlamlı düzeyde daha fazla kullandıkları söylenebilir.

Türkçe hazırlık sınıfı öğrencilerinin öğrenme yaklaşımlarının yaş değişkenine göre anlamlı düzeyde farklılık göstermediği görülmektedir. Buna göre öğrencilerin öğrenme yaklaşımları üzerinde yaşın anlamlı bir etkisinin olmadığı söylenebilir.

Öğrencilerin öğrenme yaklaşımlarının kitap, gazete ve dergi okuma değişkenine göre sadece yüzeysel yaklaşım alt boyutunda anlamlı farklılaşma gösterdiği görülmektedir $(\mathrm{t}(170))=2,122, \mathrm{p}<.05)$. Buna göre Yüzeysel Yaklaşım alt boyutunda kitap, gazete ve dergi okuyanların aritmetik ortalamasının ( $\bar{X}=66,24)$ ve okumayanların aritmetik ortalamasının ise $(\bar{X}=60,94)$ olduğu ve Türkçe kitap, gazete ve dergi okuyanların okumayanlara göre yüzeysel yaklaşımı daha fazla tercih ettikleri söylenebilir.

Türkçe hazırlık sınıfı öğrencilerinin en iyi olduklarını düşündükleri beceri alanı değişkenine göre öğrenme yaklaşımları arasında anlamlı farklılaşma olmadığı görülmektedir. Buna göre öğrencilerin öğrenme yaklaşımları üzerinde en iyi olduklarını düşündükleri beceri alanı değişkeninin anlamlı bir etkisinin olmadı̆̆ söylenebilir.

Türkçe hazırlık sınıfı öğrencilerinin en iyi olduklarını düşündükleri beceri alanı değişkenine göre öğrenme yaklaşımları arasında anlamlı farklılaşma olmadığı görülmektedir. Buna göre öğrencilerin öğrenme yaklaşımları üzerinde en iyi olduklarını düşündükleri beceri alanı değişkeninin anlamlı bir etkisinin olmadı̆̆ söylenebilir.

Öğrencilerin öğrenme yaklaşımlarının önceden Türkçe eğitim almış olma değişkenine göre anlamlı olarak farklılaşma göstermediği görülmektedir. Elde edilen bu bulgu doğrultusunda önceden Türkçe eğitim almış olmanın öğrenme yaklaşımları üzerinde anlamlı bir etkiye sahip olmadığı söylenebilir.

Öğrencilerin öğrenme yaklaşımlarının Türkçe öğrenmenin zorluğuna ilişkin düşüncelerine göre anlamlı olarak farklılaşma göstermediği görülmektedir. Elde edilen bu bulgu doğrultusunda Türkçe öğrenmenin zorluğuna ilişkin düşüncelerin öğrenme yaklaşımları üzerinde anlamlı bir etkiye sahip olmadığı söylenebilir.

Öğrencilerin öğrenme yaklaşımlarının Türkçe televizyon yayını izleme değişkenine göre anlamlı olarak farklılaşma göstermediği görülmektedir. Elde edilen bu bulgu doğrultusunda Türkçe televizyon yayını izlemenin öğrenme yaklaşımları üzerinde anlamlı bir etkiye sahip olmadığı söylenebilir.

Öğrencilerin öğrenme yaklaşımlarının Türkçe yazma değişkenine göre anlamlı olarak farklılaşma göstermediği görülmektedir. Elde edilen bu bulgu doğrultusunda Türkçe yazı yazmanın öğrenme yaklaşımları üzerinde anlamlı bir etkiye sahip olmadığı söylenebilir.

$\mathrm{Bu}$ çalışmada, Türkçe hazırlık öğrenimi görmekte olan yabancı uyruklu öğrencilerin öğrenme yaklaşımlarına ilişkin çeşitli değerlendirmelerde bulunulmuş ve elde edilen sonuçlardan hareketle bazı 
öneriler sunulmuştur. Araştırma sonucu, literatürde yapılan diğer araştırma bulgularını destekler niteliktedir.

Türkçe hazırlık öğrenimi görmekte olan yabancı uyruklu öğrencilerin birçoğu farklı ana dillerine, kültürlere ve farklı sosyolojik, demografik özelliklere sahip kişilerdir. Bunun bir sonucu olarak da öğrenme yaklaşımları diğer birçok etmen gibi çeşitlilik göstermektedir. Çolak (2006), çalışmasında iş birliğine dayalı öğrenme türünü dikkate alarak öğrenme-öğretme süreci yönüyle önemli olan öğrenme yaklaşımlarının, öğrenme kalıcılığı ve akademik başarı üzerindeki etkisini belirlemeyi hedeflemiştir. Kızılgüneş’in (2007) çalışmasının amacı ise, 6. sınıf öğrencilerinin sınıflandırma konusundaki başarıları üzerinde, onların epistemolojik inançlarının, motivasyonlarının ve öğrenme yaklaşımlarının ne kadar etkili olduğunu belirlemektir. Ekinci (2008) çalışmasında, üniversite öğrencilerinin öğrenme yaklaşımlarını tercih etme düzeylerini belirlemeye ve öğrenme-öğretme süreci değişkenleriyle öğrenmeöğretme ortamının özellikleri, üniversite, konu alanı, mezun olunan okul türü, sınıf, cinsiyet, başarı düzeyi ve ilişkilerini ortaya koymaya çalışmaktadır. Çünkü her toplumun ve dilin farklı özellikleri olduğundan hareketle yabancılara Türkçe öğretirken bu düşüncenin sürekli göz önünde bulundurulması ve öğrencilerin öğrenme yaklaşımı tercihlerinin dikkate alınması gerekmektedir.

Türkçe hazırlık öğrenimi görmekte olan yabancı uyruklu öğrencilerin öğrenme yaklaşımlarındaki tercihlerinin çoğunlukla derinlemesine öğrenme yaklaşımı olmasına karşın diğer yaklaşımları tercih edenlerin sayılarının da yadsınamayacak düzeyde olduğu göz önünde tutulmalı (Kılınç, 2013); derinlemesine öğrenme yaklaşımı tercih düzeyine çıkartılamıyorsa onların tercihlerine uygun yöntemlerin de uygulanması gerekmektedir. Öğrencilerin öğrenme yaklaşımlarının istenilen düzeye getirilebilmesi için gerekli olan altyapı ve donanım için imkânların geliştirilmesi, özellikle üniversitelerdeki öğrenme-öğretme ortamlarının bu algıyı sağlayacak ve artıracak şekilde yeniden düzenlenmesi gerekmektedir.

Yabancılara Türkçe öğretiminde yaklaşım, yöntem ve teknikler belirlenirken hedef kitlenin özellikleri ve dersin amaçları dikkate alınmalı, bu hususlar üzerinde gerekli tartışmalar yapılarak mümkün olan en iyiler tercih edilmelidir. Yılmaz (2009), tarafından gerçekleştirilen araştırmada ise karma öğrenme ortamında eğitim gören üniversite öğrencilerinin öğrenme yaklaşımlarına göre web materyallerini kullanma davranışları, akademik başarıları, ortama yönelik memnuniyetleri ve derse devamları değerlendirilmektedir. Elde edilen sonuçlara göre; derinlemesine öğrenme yaklaşımını tercih eden öğrencilerin karma öğrenme ortamından duydukları memnuniyet düzeyleri yüzeysel öğrenme yaklaşımına sahip öğrencilerden anlamlı derecede yüksek olduğu belirlenmiştir (Demir, 2013). Uygulanabilirlik ve yararlılık yönleri sürekli tartışmalı olan klasik yöntemlerdense ezber yapmayı değil öğrenmeyi öngören, kalıcılı̆̆ı ve yaygın dile uygunluğu daha fazla olan çağdaş yöntemler tercih edilmelidir.

$\mathrm{Bu}$ araştırma, öğrenme yaklaşımlarına yönelik ve $\mathrm{C} 1$ düzeyindeki öğrenciler üzerine gerçekleştirilmiş olsa da aktarılan bilginin yaklaşımla ilgili olması noktasında diğer özellikler ve düzeyler için de benzer çalışmalar yapılmalı ve sonuçlar mukayeseli bir şekilde ele alınmalıdır.

Araştırmanın sonuçlarından da hareketle Türkçeyi yabancı dil olarak öğrenenlerin akademik başarılarını yükselmesiyle öğrenme yaklaşım tercihleri arasında anlamlı ilişki bilinmektedir (Canıdemir, 2013). Bu da uygulayıcılarla ve öğrenme-öğretme ortamıyla yakından ilişkilidir. Teorik ve uygulamalı olarak yabancılara Türkçe öğretimine vakıf olmayan pedagojik yönü zayıf uygulayıcıların bunu sağlayabilme olanakları bulunmadığı için bu kapsamda MEB, YÖK gibi kurumlardan destek 
alınmalıdır. DİLMER, TÖMER gibi kurumlardan daha tecrübeli olanları ve Eğitim Fakültelerinin ilgili bölümleri de yeni açılan kurumlara ve yeni başlayan uygulayıcılara yönelik hizmet öncesi ve hizmet içi eğitimlerin yanı sıra farkındalık yaratma ve başarıya ulaşma noktasında üzerine düşen görevi yerine getirmelidir.

Yabancılara Türkçe öğretiminde derinlemesine ve stratejik öğrenme yaklaşımlarının etkili olacağı, öğrenen merkezli, öğrenci-öğretmen ve öğrenci-öğrenci etkileşimli dersler yapılmalı, teknolojik destekli U oturma düzenindeki dersliklerde, yaygın dil ve kültürün somut ögeleriyle yapılan çalışmalara ağırlık verilmelidir.

Türkçe öğrenen yabancı uyruklu öğrencilerin öğrenme yaklaşımları üzerinde birçok dilin, kültürün ve etmenin rol oynayabileceği düşüncesinden hareketle bu ve benzeri çalışmaların farklı örneklemler üzerinde de yapılması yararlı olacaktır.

\section{Kaynakça}

Beattie, V., Collins, W. \& McInnes, W. (1997). Deep and surface learning: Simple or simplistic dichotomy. Accounting Education, 6(1), 1-12.

Beydoğan, Ö. (2008). Derinliğine ve yüzeysel öğrenmede kavram haritaları ve şemaların işlevi. Millî Eğitim, 173, 258-270.

Biggs, J. B. (1987). Student approaches to learning and studing. Melbourne: Australian council for educational research.

Biggs, J., Kember D. \& Leung, D. Y. P. (2001). The revised two factor study process questionnaire. British Journal of Educational Psychology, 71, 133-149.

Büyükikiz, K. K. (2011). Türkçeyi yabancı dil olarak öğrenenlerin yazma becerileri ile öz yeterlilik algıları arasındaki ilişki üzerine bir araştırma. Yayımlanmamış doktora tezi. Ankara: Gazi Üniversitesi Eğitim Bilimleri Enstitüsü.

Büyüköztürk, Ş., Kılıç Çakmak, E., Akgün, Ö. E., Karadeniz, Ş. \& Demirel, F. (2008). Bilimsel araştırma yöntemleri. Ankara: Pegem Yayınları.

Canıdemir, A. (2013). Ortaöğretim öğrencilerinin öğrenme yaklaşımları ve başarı amaç yönelimlerinin akademik başarı ile ilişkisinin incelenmesi. Yüksek lisans tezi. Ankara: Ankara Üniversitesi Eğitim Bilimleri Enstitüsü.

Çolak, E. (2006). İş birliğine dayalı öğretim tasarımının öğrencilerin öğrenme yaklaşımlarına, akademik başarılarına ve öğrenmenin kalıcılığına etkisi. Yayımlanmamış doktora tezi. İstanbul: Yıldız Teknik Üniversitesi Sosyal Bilimler Enstitüsü.

Çolak, E. \& Fer, S. (2007). Öğrenme yaklaşımları envanterinin eş değerlik, güvenirlik ve geçerlik çalışması. ÇÜ Sosyal Bilimler Enstitüsü Dergisi, 16(1), 197-212.

Demir, S. (2013). Farklılaștırılmıș öğretim yöntemlerinin öğrencilerin akademik başarı, öğrenme yaklaşımları ve kalıcılık puanları üzerindeki etkisi. Yayımlanmamış doktora tezi. İstanbul: Yıldız Teknik Üniversitesi Sosyal Bilimler Enstitüsü.

Demirel, Ö. (2000). Kuramdan uygulamaya eğitimde program geliştirme. Ankara: Pegem Yayınları.

Ekinci, N. (2008). Üniversite öğrencilerinin öğrenme yaklaşımlarının belirlenmesi ve öğretme-öğrenme süreci değişkenleri ile ilişkileri. Yayımlanmamış doktora tezi. Ankara: Hacettepe Üniversitesi Sosyal Bilimler Enstitüsü.

Entwistle, N. J. \& Ramsden, P. (1983). Understanding student learning. Australia: Croom Helm Ltd.

Er, O., Biçer, N. \& Bozkırlı, K. Ç. (2012). Yabancılara Türkçe öğretiminde karşılaşılan sorunların ilgili alanyazını ışığında değerlendirilmesi. Uluslararası Türkçe Edebiyat Kültür Eğitim Dergisi, 2, 5169. 
Felder, R. M. \& Brent, R. (2005). Understanding student differences. Journal of Engineering Education, 94(1), 57-72.

Jackson, B. (1994). Assesment practices in art and design: a contribution to student learning? In: Graham Gibbs (Ed.), Improving student learning. Assessment and Evaluation Oxford: Oxford Centre for Staff Development.

Karasar, N. (2012). Bilimsel araştırma yöntemi. Ankara: Nobel Yayınları.

Kılıç, D. (2009). Öğrencilerin genetik kavramları anlama düzeyleri ile mantıksal düşünme yetenekleri ve öğrenme yaklaşımları arasındaki ilişki. Yayımlanmış doktora tezi. Ankara: Hacettepe Üniversitesi Fen Bilimleri Enstitüsü.

Kılınç, M. (2013). Genel lise öğrencilerinin öğrenme yaklaşımlarının çeşitli değişkenler açısından incelenmesi. Yüksek lisans tezi. Kayseri: Erciyes Üniversitesi Eğitim Bilimleri Enstitüsü.

Kızılgüneş, B. (2007). Öğrencilerin sınıflandırma konularındaki başarılarının epistemolojik inançlar, motivasyon ve öğrenme yaklaşımları ile tahmini. Yüksek lisans tezi. Ankara: Orta Doğu Teknik Üniversitesi Sosyal Bilimler Enstitüsü.

Marshall, D. \& Case, J. (2007). Approaches to learning' research in higher education: A response to Haggis. British Educational Research Journal, 31(2), 257-267.

Marton, F. \& Saljo, R. (1976). On qualitative differences in learning. Outcome and process. British Journal of Educational Psychology, 46, 4-11.

Newble, D. I. \& Entwistle, N. J. (1986). Learning styles and approaches: Implications for medical education. Medical Education, 20, 162-175.

Ozan, C., \& Çiftçi, M. (2013). Eğitim fakültesi öğrencilerinin öğrenme yaklaşımları tercihleri ve öğrenmeye ilişkin algılarının incelenmesi. Pegem Eğitim ve Öğretim Dergisi, 3(1), 55-66.

Ramsden, P. (1979). Student learning and perceptions of the academic environment. Higher Education, $8(4), 411-427$.

Ramsden, P. (1992). Learning to teach in higher education. London: Routledge.

Scouller, K. (1998). The influence of assessment method on students' learning approaches: Multiple choice question examination versus assignment essay. Higher Education, 4(4), 453-72.

Senemoğlu, N. (2011). Eğitim fakültesi öğrencilerinin öğrenme yaklaşımları ve çalışma becerileri. Eğitim ve Bilim, 36(160), 65-80.

Şat, M. (2013). BÖTE lisans öğrencilerinin biçimlendirici geri bildirime yönelik alglları ve tercihleri ile bu algı ve tercihlerin öğrenme yaklaşımlarıyla olan ilişkisi. Yüksek lisans tezi. Ankara: Orta Doğu Teknik Üniversitesi Fen Bilimleri Enstitüsü.

Tait, H., Entwistle, N. J., \& McCune, V. (1998). ASSIST: A reconceptualisation of the approaches to studying inventory. In C. Rust (Ed.), Improving student learning: Improving students as learners. Oxford: Oxford University.

Vermunt, J. D. (1994). Inventory of learning styles in higher education; scoring key for the inventory of learning styles in higher education. Tilburg: Tilburg University.

Yılmaz, B. (2009). Karma öğrenme ortamındaki üniversite öğrencilerinin öğrenme yaklaşımlarına göre ders başarılarının, derse devamlarının, web materyalini kullanma davranışlarının ve ortama yönelik memnuniyetlerinin değerlendirilmesi. Yayımlanmamış doktora tezi. İstanbul: Yıldız Teknik Üniversitesi Sosyal Bilimler Enstitüsü.

Zhang, L. \& Stenberg, R. J. (2000). Are learning approaches and thinking styles related? A study in two Chinese populations. The Journal of Psychology, 134(5), 469-89. 